\title{
Preparation and Sintering Behaviour of Alumina Powder by Ammonia Precipitation Method
}

\author{
Liuyan Wang ${ }^{1,2, a}$ \\ ${ }^{1}$ School of Architecture and civil engineering, Shenyang University, 110044, China \\ 2 Key Laboratory for advanced materials of Liaoning province, Shenyang University, 110044, China
}

\begin{abstract}
In this paper, alumina precursor was prepared by the ammonia precipitation method which used $\mathrm{Al}\left(\mathrm{NO}_{3}\right)_{3} 9 \mathrm{H}_{2} \mathrm{O}$ as aluminum source and $\mathrm{NH}_{4} \mathrm{OH}$ as a precipitator, adding a small amount of PEG4000 as the surface active agent. Finally $\gamma-\mathrm{Al}_{2} \mathrm{O}_{3}$ was obtained at $900^{\circ} \mathrm{C}$ for $2 \mathrm{~h}$. The stable alumina crystal form of $\alpha-\mathrm{Al}_{2} \mathrm{O}_{3}$ was got at $1100^{\circ} \mathrm{C}$ for $2 \mathrm{~h}$. The influence of precipitation agent on the precursor was studied by means of TG / DTA and Tem, XRD etc. The effects of the synthesis temperature and time on the phase composition and morphology of the alumina powder were also analysed.
\end{abstract}

\section{Introduction}

Alumina powder as one of the special functional materials, due to the high purity, fine particles and uniformly distributed, it has a broad prospect of application on the ceramic structure, catalyst carrier, fine ceramics for its small size, surface and quantum effect[1].

Preparation of nano alumina powder by precipitation method $[2,3,4]$ has the advantages of low cost, high purity, large amount of production, simple equipment manufacturing and short process. At present, the main precipitation method for preparing alumina powder was used ammonia and urea as precipitation agent,by the reaction of aluminum ions and precipitation agent directly generated $\gamma$ $\mathrm{AlO}(\mathrm{OH})$, and then sintered this alumina precursor[5].

Based on the preliminary work [6,7], the process parameters such as thermal analysis, synthesis temperature and reaction time were studied by using ammonia precipitation method which took aluminum nitrate as raw material. This method had the advantages of simple process, low cost and short process flow, and it was suitable for the preparation of nanometer powder in the process of industrial production.

\section{Experiments}

\subsection{Raw materials}

Raw materials used in this experiment was shown in Table.1.

\footnotetext{
${ }^{\text {a }}$ Corresponding author: w.ly428@163.com
} 
Table.1 Raw materials of experiments

\begin{tabular}{|c|c|c|c|}
\hline Reagent name & $\begin{array}{c}\text { Molecular } \\
\text { formula }\end{array}$ & Specifications & Manufacturer \\
\hline ammonia & $\mathrm{NH}_{3} \cdot \mathrm{H}_{2} \mathrm{O}$ & A.R & $\begin{array}{c}\text { Shenyang } \\
\text { Chemical } \\
\text { Reagent } \\
\text { Factory. }\end{array}$ \\
\hline $\begin{array}{c}\text { Polyvinyl } \\
\text { alcohol }\end{array}$ & $\mathrm{PEG} 4000$ & A.R & $\begin{array}{c}\text { Tianjin kermel } \\
\text { chemical } \\
\text { reagent }\end{array}$ \\
\hline $\begin{array}{c}\text { Aluminum } \\
\text { nitrate }\end{array}$ & $\begin{array}{c}\mathrm{Al}\left(\mathrm{NO}_{3}\right)_{3} \cdot 9 \\
\mathrm{H}_{2} \mathrm{O}\end{array}$ & A.R & $\begin{array}{c}\text { Shenyang } \\
\text { Chemical } \\
\text { Reagent } \\
\text { Factory }\end{array}$ \\
\hline $\begin{array}{c}\text { Absolute } \\
\text { alcohol }\end{array}$ & $\mathrm{C}_{2} \mathrm{H}_{5} \mathrm{OH}$ & A.R & $\begin{array}{l}\text { Shenyang } \\
\text { Chemical } \\
\text { Reagent } \\
\text { Factory }\end{array}$ \\
\hline
\end{tabular}

\subsection{Experiment method}

Using $\mathrm{Al}\left(\mathrm{NO}_{3}\right)_{3} \cdot 9 \mathrm{H}_{2} \mathrm{O}$ as aluminum source, $\mathrm{NH}_{4} \mathrm{OH}$ as precipitator, a small amount of PEG4000 was added in the experiment as the surface active agent to prevent the aggregation of the product particles.In order to reduce growth rate of the nucleation, the experimental temperature should be controlled below $10{ }^{\circ} \mathrm{C}$, dropping speed was controlled at $3 \sim 5 \mathrm{ml} / \mathrm{min}$, and the end point $\mathrm{pH}$ value was kept between 7 and 8 .

After the end of the titration, the preparation of the precursor solution was prepared by aging and centrifugation, and then washed with anhydrous ethanol.

Finally, the resulting sample was placed in a rapid heating furnace, with a temperature of $10^{\circ} \mathrm{C} / \mathrm{min}$ rise to $900^{\circ} \mathrm{C}$ for $2 \mathrm{~h}$, the sample was token with the furnace cooling, and finally ultra-fine alumina powder was got.

\section{Results and discussion}

\subsection{Effect of dispersant on particle size and morphology}

Surface active agent as a good chemical dispersants can be adsorbed on the surface of the powder particles. It made the inter particles difficult to reunite and made the powder dispersed by electrostatic repulsion and VDW[8,9,10]. Some research results shown that PEG4000 can form a uniform and thick protective film on the surface of the colloid, which can restrain the aggregation of colloidal particles very effectively[11]. Therefore, PEG4000 was used as a dispersant to prepare ultrafine alumina powders.

\subsection{TG-DSC comprehensive thermal analysis of alumina precursor}

The TG-DSC curve of alumina precursor prepared by ammonia as precipitator was shown in Figure 1. With the increase of sintering temperature, weightlessness of $\mathrm{Al}(\mathrm{OH})_{3}$ was a continuous process when the temperature was below $700^{\circ} \mathrm{C}$. The curve showed a continuous decline in this process. When the temperature was higher than $700^{\circ} \mathrm{C}$, the TG curve was almost a horizontal curve. This horizontal curve indicated that the decomposition of $\mathrm{Al}(\mathrm{OH})_{3}$ was over. The TG curve was in a horizontal state 
for the $\mathrm{Al}(\mathrm{OH})_{3}$ has begun to phase transformation, and the phase change process was a constant weight process.

An obvious endothermic peak was appeared in the DSC curve at $133.46^{\circ} \mathrm{C}$. The adsorption water was divided from the sample. Endothermic peaks was appeared nearly $207.80^{\circ} \mathrm{C}$ for the volatilization of residual organic matter in the sample. A strong endothermic peak appeared at $245.98^{\circ} \mathrm{C}$ for the alumina precursor was appeared the following decomposition reaction, see formula (1):

$$
\mathrm{Al}(\mathrm{OH})_{3} \rightarrow \mathrm{AlOOH}+\mathrm{H}_{2} \mathrm{O}
$$

Water produced by the decomposition reaction was overflowed in the form of water vapor. With the increase of temperature, a strong exothermic peak was appeared at $299.77^{\circ} \mathrm{C}$ for $\mathrm{AlOOH}$ was generated from the decomposition reaction, see formula (2). TG curves between $200^{\circ} \mathrm{C}$ to $300^{\circ} \mathrm{C}$ sharp declined for $\mathrm{AlOOH}$ was changed to $\mathrm{Al}_{2} \mathrm{O}_{3}$ and Decomposition of water was evaporated from the sample.

$$
2 \mathrm{AlOOH}=\mathrm{Al}_{2} \mathrm{O}_{3}+\mathrm{H}_{2} \mathrm{O}
$$

When the heating temperature rises to $1107^{\circ} \mathrm{C}$ and $1163^{\circ} \mathrm{C}$ respectively, two obvious endothermic peak were correspondingly appeared on the DSC curve. There was no obvious phenomenon of weightlessness in the TG curve. Stable alumina crystal can be obtained at $1000^{\circ} \mathrm{C}$.

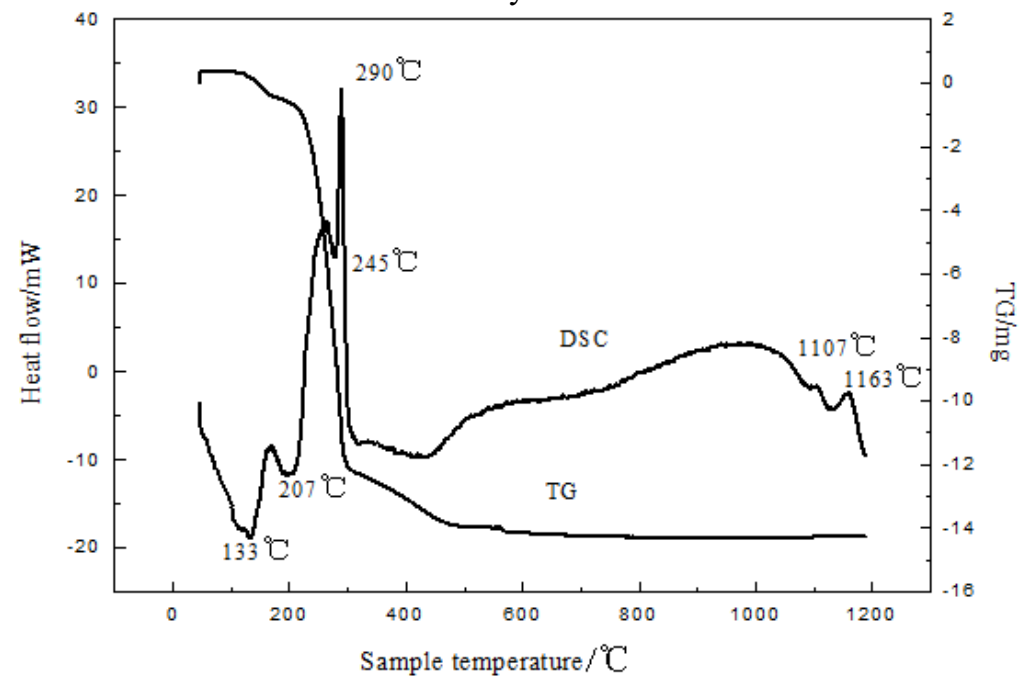

Figure 1. TG-DSC curve of $\mathrm{Al}_{2} \mathrm{O}_{3}$ precursor prepared by ammonium hydroxide

\subsection{Effect of calcination temperature on the phase composition of alumina}

The XRD diagram of alumina precursor prepared by ammonia water as the precipitation agent at different temperatures was shown in Figure 2. Amorphous $\mathrm{Al}_{2} \mathrm{O}_{3}$ was obtained when the sintering temperature reached $800^{\circ} \mathrm{C}$ for $2 \mathrm{~h}$ as shown from Fig.2[12].

$\gamma-\mathrm{Al}_{2} \mathrm{O}_{3}$ was got when the temperature rises to $900^{\circ} \mathrm{C}$ for $2 \mathrm{~h} . \gamma-\mathrm{Al}_{2} \mathrm{O}_{3}, \delta-\mathrm{Al}_{2} \mathrm{O}_{3}, \alpha-\mathrm{Al}_{2} \mathrm{O}_{3}$ and other types of crystal were appeared at $1000^{\circ} \mathrm{C}$. The precursor was almost completely converted to $\alpha-\mathrm{Al}_{2} \mathrm{O}_{3}$ at $1100^{\circ} \mathrm{C}$. This phenomenon showed that with temperature increased, the composition of the structure changed obviously. And the stability of the structure was increased. Finally, the structure of $\alpha-\mathrm{Al}_{2} \mathrm{O}_{3}$ with stable crystal structure was obtained. 

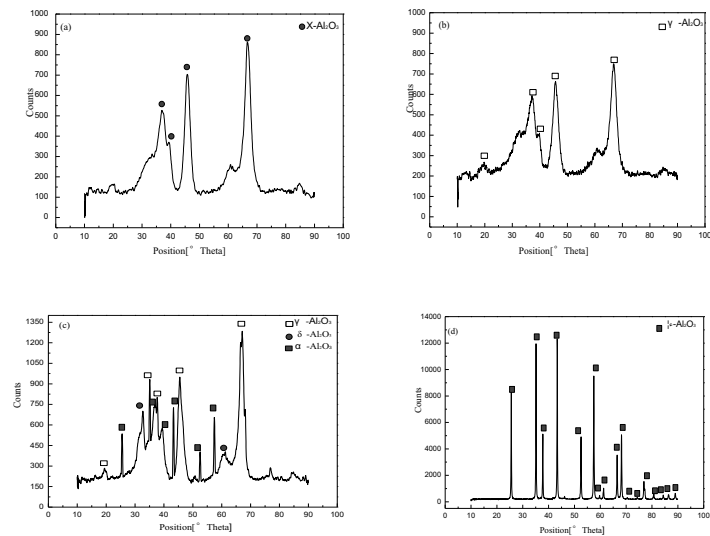

Figure 2. XRD pattern at different calcination temperature preparedby ammonium hydroxide

\subsection{Effect of sintering time on the weight loss rate of alumina powder}

The sintering temperature range was determined by the comprehensive thermal analysis of alumina precursor. In order to determine the reasonable holding time, a certain amount of alumina precursor was taken under $900^{\circ} \mathrm{C}$ and incubated for 1 hour, 1.5 hours, 2 and 2.5 hours. The relationship between the powder weight loss rate and the sintering time was as shown below in Fig.3. The weight loss rate of the powder was basically unchanged at $900^{\circ} \mathrm{C}$ for 2 hours compared with followed sintering time. Therefore, 2 hours of the sintering time was chosen due to the aggregation and growth of grains can be avoided.

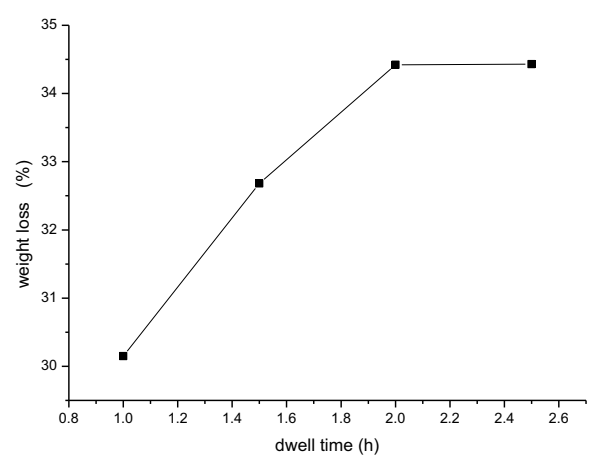

Figure 3. Relation between weight loss and dwell time

\subsection{Effect of calcination temperature on particle size and morphology of alumina powder}

The relationship between different calcinationtemperature and average particle size of alumina powder prepared by using ammonia as precipitator was shown in Fig. 4.

The different sintering temperature had a significant effect on the particle size of alumina. At the same sintering time, with the increase of the sintering temperature, the relationship between the sintering temperature and the average particle size firstly decreased, then increased followed by decreasing. And the minimum size of the particle size was obtained at $900{ }^{\circ} \mathrm{C}$. 


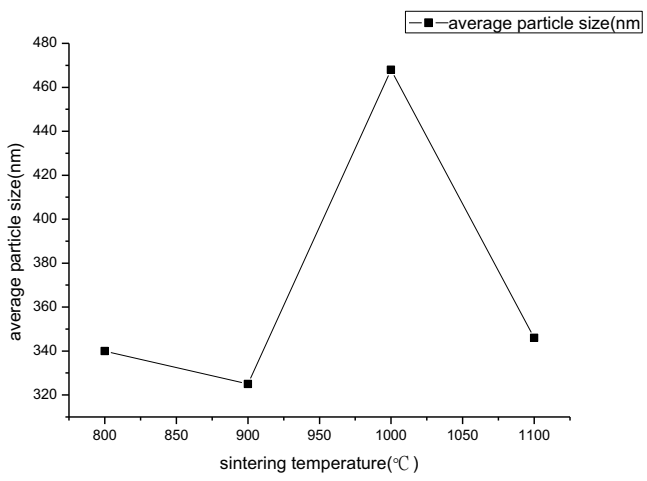

Figure 4. Relationship between different sintering temperature and average particle size with ammonia as precipitator

The nano scale spherical alumina powder can be obtained from alumina precursor sintered by $900{ }^{\circ} \mathrm{C}$ for 2 hours, as shown in Fig.5.

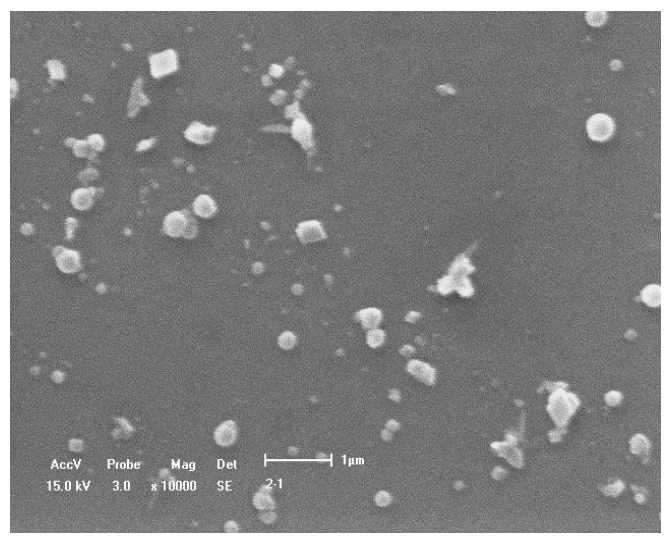

Figure 5. $\mathrm{SEM}$ image of $\mathrm{Al}_{2} \mathrm{O}_{3}$ powder prepared by ammonium

\section{Conclusions}

Nano alumina particles was got from the dried precursor by sintering $900^{\circ} \mathrm{C}$ after 2 hours. Alumina precursor was prepared which used $0.3 \mathrm{~mol} / 1$ aluminum nitrate as raw material and 1:2 ammonia as precipitator, adding a certain amount of dispersant. In this precipitation process, temperature was controlled below 10 degrees. And $\mathrm{pH}$ was between 7 and 8 .

After adding the dispersant PEG4000, fine particle size, appearance and good dispersion of the alumina powder can be obtained. In the sintering process of alumina precursor, the crystal components increased gradually, and the crystal composition increased with the increase of the sintering temperature. A stable crystal structure of the $-\mathrm{Al}_{2} \mathrm{O}_{3}$ can be obtained with ammonia as the precipitation agent prepared by the alumina precursor sintered at $1100^{\circ} \mathrm{C}$ for $2 \mathrm{~h}$.

\section{References}

1. T.Zhu,F.M.Wang,X.D.Wang,etc. Progress and application of nanometer materials in foreign countries. Chemical Industry Press,2002. 
2. Y.J.Wang, C.X.Lee, Z.H.Wang. Preparation of nano alumina particles by ultrasonic chemical precipitation method. Journal of Beijing chemical industry, 29(2002).

3. Y.F.Chang, G.L.Ning, Y.Lin. Application of a new type of temperature resistant surface active agent in the preparation of spherical alumina nano powder. Powder technology in China, 6(2000).

4. I.N.Bhattacharya, P.K.Gochhayat, P.S.Mukherjee, etal. Thermal decomposition of precipitated low bulk density basic aluminium sulfate.Materials Chemistry and Physis, 88(2004).

5. A.F.Zhang,J.P.Liu. Study on the new technology of preparing nano alumina powder by precipitation method, Inorganic Chemicals industry, 35(2003).

6. Y.Q.Wu, Y.F.Zhang, X.X.Huang. Preparation of nano $\alpha-\mathrm{Al}_{2} \mathrm{O}_{3}$ powders at low temperature, Journal of inorganic materials.16(2001).

7. P.Wang, D.Z.Wei. Kinetic Analysis on Preparation of Micro Power Aluminum Hydroxide by Liquid Precipitation Process, Journal of Northeastern University(Natural Science), 35(2014).

8. X.J.Sun. Study on the Application of surfactants in preparation and dispersion of Ultrafine Alumina, Powder Metallurgy Technology.33(2015).

9. G.H.Liu, Y.M.Zhang, X.B.Lee. Agglomeration Mechanism of surfactant of ultra-fine $\mathrm{Al}(\mathrm{OH})_{3}$ in drying process, The Chinese Journal of Nonferrous Metals, 19(2009).

10. S.Y.Lu, Y.Q.He. Application of sursurfactant to synthesis of nano-alumina, Materials review, 5(2006).

11. F.GU, Y.Shen, C.Xu, etc. The influence of polymerization degree of dispersing agent on the power properties of nano alumina, Functional material, 36(2005).

12. L.D. Shang. Preparation and identification of eight kinds of crystal alumina, Chemical world, 7(1994). 